\title{
A atuação de relações públicas nas ações de responsabilidade social das organizações
}

The role of Public Relations on organizations's social responsibility actions

Cleuza G. Gimenes Cesca

Professora Titular e Pesquisadora da Puc-Campinas, Doutora em Ciências da comunicação pela USP.

E-mail: cggcesca@yahoo.com.br

Resumo

Visando detectar qual a atuação de relações públicas nas ações de responsabilidade social das organizaçōes, fez-se estudo de casos de duas empresas do $2^{\circ}$ setor, que contêm em seus organogramas o setor de relações públicas com profissional da área atuando; e duas do $3^{\circ}$ setor, que também possuem o setor e profissional de relações públicas em seus quadros.

0 recorte feito, tendo como amostra a cidade de Campinas/SP e região próxima, confirma as pesquisas nacionais, inéditas, feitas pelo IPEA, quanto à forte e crescente participação do $2^{\circ}$ setor no social. As organizações do $3^{\circ}$ setor também comprovam esse interesse do $2^{\circ}$ setor.

Quanto à atuação de relações públicas, foi possível observar que o setor tem participação na implementação das açōes de responsabilidade social das organizações do $2^{\circ}$ setor e também atua nas organizações do $3^{\circ}$ setor, mas é preciso avançar muito mais.

Palavras-chave: Relações Públicas; Responsabilidade Social; Pesquisa.

Introdução

A Responsabilidade Social vem sendo exercida em larga escala em todo o planeta. No Brasil, a cidadania empresarial também está sendo vista pelas organizações em geral como uma oportunidade de colaborar para a construção de uma sociedade mais humana. Nesse caminhar para um engajamento é possível perceber que todos são responsáveis pela sociedade que se quer; portanto, o bem da coletividade é uma meta que o trabalho em parceria com instituições públicas, privadas e do terceiro setor pode ser alcançada. Isso se tornou uma realidade ainda mais palpável a partir de 02/01/05, quando o presidente Luiz Inácio Lula da Silva sancionou a Lei das PPPs (Parcerias Público-Privadas). ${ }^{1}$

Peroba Filho (in Esteves, 2000, p.15) afirma:

'Mais informações sobre as PPPs em www.businersonline.com.br
Acho que uma das primeiras coisas que o leitor deve considerar quando se vê diante da questão da responsabilidade social é se perguntar: eu devo fazer isto só porque é correto do ponto de vista dos interesses de todas as partes interessadas no meu empreendimento?

A resposta, positiva ou não, que qualquer organização daria seria que deve fazer isso porque é correto do ponto de vista dos interesses de todas as partes interessadas na organização. Naturalmente, as organizações têm claro que essa atitude de empresa cidadã repercutirá positivamente sobre seus dividendos, pois sabem elas que o consumidor de nossos dias está optando por produtos e serviços de empresas com esse comportamento. Silva (in Esteves, 2000, p.180) vem confirmar essa tese, afirmando:

Quanto mais uma empresa for socialmente responsável, maiores serão suas chances de manter e ampliar a sua base de clientes. Se ela não polui, se contribui para a 
sociedade como um todo, se patrocina um projeto social sustentável, então ela passa a ser objeto de orgulho por parte dos colaboradores que nela trabalham e amplia a sua sustentação junto aomercado. p.130),

Para Margarida Kunsch (2003,

Hoje o indivíduo, mais consciente de seus direitos e deveres, percebe que pode e deve participar do processo de construção de uma sociedade mais justa, sabedor de que o Estado sozinho não dá conta de cumprir a sua missão. Eas organizações, por sua vez, são convidadas a exercer novos papéis na construção da cidadania, sendo muito grande o número de programas ligados a projetos sociais e a parcerias com o terceiro setor.

Os institutos Ethos ${ }^{2}$ e Akatu e a Indicator GfK divulgaram, em 15 de dezembro 2004, o relatório Responsabilidade Social das Empresas Percepção do Consumidor Brasileiro, Pesquisa 2004 ${ }^{3}$, que aferiu a percepção dos consumidores brasileiros sobre o papel social das empresas, bem como suas expectativas sobre a contribuição empresarial para o desenvolvimento econômico e social.

A pesquisa ouviu mil pessoas nas regiões metropolitanas de Belém, Belo Horizonte, Curitiba, Distrito Federal, Fortaleza, Goiânia, Porto Alegre, Recife, Rio de Janeiro, Salvador e São Paulo. Entre os temas abordados no levantamento, destacamse as questões ligadas à globalização, à economia, ao envolvimento das empresas com os problemas sociais e à confiança nas instituições.

$\mathrm{O}$ estudo revela que vem se cristalizando entre os consumidores a percepção de que as empresas devem contribuir para a construção de uma sociedade melhor: $44 \%$ dos entrevistados acreditam que as empresas devem ir além do que é determinado por lei, para atingir padrões éticos mais elevados e realizar plenamente seu papel da sociedade. Esse índice foi de $35 \%$ em levantamento realizado no ano 2000 e de $39 \%$ em 2002 . "Isto demonstra que adotar a gestão socialmente responsável como estratégia de negócios atende uma parcela cada vez mais significativa dos consumidores brasileiros", diz Oded Grajew, presidente do Instituto Ethos. E continua: "O engajamento das empresas nos problemas sociais do País tende a ser uma preocupação cada vez mais ampla, atingindo todos os segmentos da sociedade".

Para Helio Mattar, diretorpresidente do Instituto Akatu, a evolução na postura do consumidor apontará novos caminhos para as empresas: "Há uma mudança de atitude em curso. O consumidor brasileiro manifesta de forma cada vez mais afirmativa sua percepção sobre a responsabilidade social empresarial", diz ele. "As empresas que desejarem ganhar ou mesmo manter seus mercados terão de se adaptar às exigências de consumidores cada vez mais conscientes".

Gutierrez (1999, p.162) afirma que: "A tendência da responsabilidade social das instituições, que parecia improvável anos atrás, consolida-se ao redor do mundo na mesma velocidade com que se dissemina a globalização, e já ganhou uma norma internacional, a SA8000, que normatiza o cumprimento das obrigações da empresa com a sociedade.

Essa Norma mencionada surgiu em 1997, pela Social Accountability International (SAI), uma ONG americana, e tem por objetivo tornar os locais de trabalho mais humanos, por meio de um padrão global passível de verificação. A conduta proposta por

\footnotetext{
${ }^{2}$ Mais detalhes www.ethos.com.br

${ }^{3} O$ relatório Responsabilidade Social das Empresas - Percepção do Consumidor Brasileiro, pesquisa 2004, integra a pesquisa internacional Corporate Social Responsability Global Public Opinion on the Changing Role of Companies, desenvolvido pela Indicator GFK, que reúne opiniões de consumidores de países como África do Sul, Alemanha, Argentina, Austrália, Brasil, Canadá, Chile, Espanha, Estados Unidos, França, GrãBretanha, Grécia, Índia, Indonésia, Itália, México, Nigéria, Rússia, Turquia e Uruguai.
} 
ela abrange temas como trabalho forçado, saúde e segurança, discriminação, horas de trabalho e compensação. Para obter certificações, a empresa se submete a um processo semelhante ao do padrão ISO, com adequação às normas e auditorias periódicas.

No Brasil existem 62 empresas com essa certificação, segundo dados do Guia Exame, de dez/2004. Em 2000, foram lançados os Indicadores Ethos, pelo Instituto Ethos, voltado para a promoção da responsabilidade social empresarial, que são atualizados anualmente. Tem por objetivo auxiliar as empresas a gerenciar seus impactos sociais e ambientais por meio de um diagnóstico que abrange temas como valores e transparências, público interno, meio ambiente, consumidores e clientes e comunidade. Para se incluir, as empresas respondem a um questionário pela internet $\mathrm{e} o$ Instituto se encarrega de avaliá-los e informar qual o desempenho da empresa em relação a seus pares. Em 2001, foi lançada a ISO 14001 , criada pela ISO-ONG que funciona por meio de institutos e que no Brasil é representada pela Associação Brasileira de Normas Técnicas (ABNT) -, que tem por objetivo definir padrões para que as empresas façam gerenciamento ambiental, minimizando continuamente os efeitos nocivos de suas atividades sobre o meio ambiente. Para aderir, a empresa deve se submeter a uma auditoria periódica para provar que essas normas foram incorporadas a seus processos. No Brasil existem cerca de 595 empresas certificadas com essa norma, segundo informações do Guia Exame de dez/2004.

A realidade tem mostrado a importância das ações de responsabilidade social para o sucesso das organizações em geral. Nesse sentido, Vassalo (in Gutierrez, 1999. p,164) afirma: "As empresas só terão sucesso a longo prazo se seus funcionários, clientes e comunidade forem bem sucedidos. Quem perceber antes esse novo momento terá uma enorme vantagem competitiva".

Acredita-se que relações públicas têm as ações de responsabilidade social já incorporadas pelas organizações como mais uma atividade para desenvolver, pois é "o esforço deliberado, planificado, coeso e contínuo da alta administração para estabelecer e manter a compreensão mútua entre a organização e todos os grupos aos quais está ligada, direta ou indiretamente" (ABRP in Cesca, 1995, p.17).

Margarida Kunsch (1997, p.142) observa que: "Não se pode limitar o trabalho de relações públicas apenas a contar e divulgar as realizações de uma organização. Esta precisa ser conscientizada de sua responsabilidade com a sociedade. Ela tem de se lembrar disso e cumprir seu papel social, não se isolando do contexto no qual se insere nem querendo usufruir a comunidade apenas para aumentar seus lucros excessivos".

Visa, portanto, este trabalho: avaliar as ações de responsabilidade social das organizações, identificar a atuação de relações públicas nesse setor e propor formas de participação de relações públicas nas ações de responsabilidade social das organizações, partindo das seguintes hipóteses: ações de responsabilidade social fortalecem a marca; as organizações socialmente responsáveis são mais valorizadas pelos consumidores; e relações públicas podem coordenar as ações de responsabilidade social das organizações.

Panorama Geral da Responsabilidade Social nas Organizações do $2^{\circ}$ Setor no Brasil. 
O IPEA- Instituto de Pesquisa Econômica Aplicada ${ }^{4}$ divulgou pesquisas inéditas que visam retratar a responsabilidade social empresarial no Brasil, as quais são utilizadas para subsidiar este trabalho.

Criado há 40 anos, o IPEA é pioneiro na disseminação de informações e conhecimentos sobre a área econômica do País. Vinculado ao Ministério do Planejamento, Orçamento e Gestão, produz pesquisas e estudos macro-econômicos, setoriais e temáticos com o intuito de subsidiar o governo na produção; análise e difusão de informações voltadas para o planejamento e a formulação de políticas. Atualmente, conta com 559 servidores. Destes, 299 são técnicos, em sua maior parte pesquisadores. Com idade média de 45 anos, $70 \%$ deles possuem doutorado e mestrado.

A idéia de uma instituição com esse objetivo surgiu em meados de 1964, quando foi criado um grupo de trabalho formado por técnicos brasileiros de alto nível e alguns consultores estrangeiros. O objetivo era estabelecer as bases de um sistema de pesquisa econômica e de planejamento para o País. Surgiu primeiro o EPEA - Escritório de Pesquisa Econômica Aplicada, em 10 de setembro de 1964, que teve como coordenador técnico o exministro do Planejamento João Paulo dos Reis Velloso. Posteriormente, o Decreto 60.457 , de 13 de março de 1967, instituiu a Fundação Instituto de Pesquisa EconômicoSocial Aplicada (IPEA). E, por fim, a partir de 17 de maio de 1990 , por meio do Decreto 99.260, a entidade passou a denominar-se Instituto de Pesquisa Econômica Aplicada.

A primeira edição da pesquisa sobre responsabilidade social empresarial no Brasil (PELIANO,
2002) foi iniciada em 1999 e concluída em 2002. Ao longo desse período, foram divulgados resultados para as cinco regiões brasileiras. A primeira região a ser pesquisada foi o Sudeste, com início em julho de 1999 e divulgação em março de 2000. Depois,

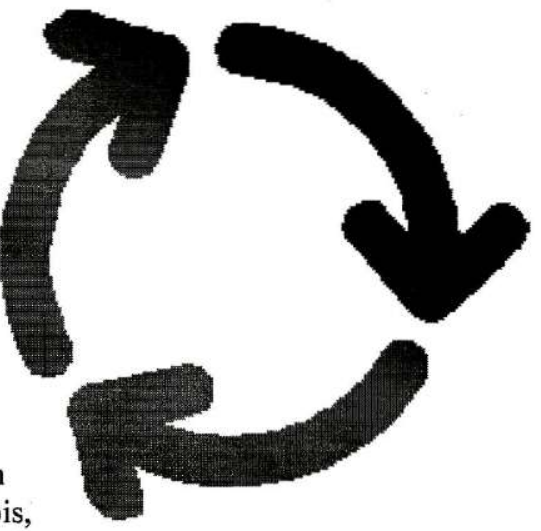
seguiram-se o Nordeste (maio-outubro 2000), Sul (julhodezembro 2000), Centro-Oeste (agosto 2001-abril 2002) e Norte (outubro 2001-junho 2002). Essa foi a primeira pesquisa a mapear a ação social das empresas de todos os portes e setores e de todas as regiões do Brasil.

$\mathrm{Na}$ segunda edição dessa pesquisa, que, por enquanto, tem apenas os primeiros resultados, o IPEA mostra que a atividade cresce ainda mais. Tem essa Segunda Edição por objetivo principal atualizar e aprofundar o conhecimento sobre as atividades ou doações que as empresas das regiões Sudeste e Nordeste realizaram em 2003, para atender às comunidades com serviços de saúde, educação, alimentação, meio ambiente, capacitação e desenvolvimento comunitário, entre outros. $\mathrm{O}$ que se quer saber é o que as empresas fizeram na área social, e que não se limitou aos benefícios concedidos aos seus empregados e familiares, e como esse comportamento tem se modificado do final da última década até os dias atuais.

Esse levantamento foi iniciado em julho de 2004, e os primeiros resultados foram divulgados em dezembro do mesmo ano. Os resultados finais têm previsão de lançamento para o primeiro semestre
${ }^{4} 0$ site www.ipea.com.br traz mais informações. 
de 2005 .

O desempenho das empresas nordestinas é o grande destaque dos resultados dessa primeira etapa. Segundo informações do levantamento, a participação das empresas na área social cresceu $35 \%$ no Nordeste, passando de $55 \%$, em 1999 , para $74 \%$, em 2003 . No Sudeste, esse incremento foi mais discreto (6\%), passando de $67 \%$ para $71 \%$ no mesmo período.

- Essas pesquisas feitas pelo IPEA têm a mais absoluta credibilidade, 0 que faz com que se conclua que a responsabilidade social no Brasil é uma realidade crescente. Mas qual tem sido a participação do Setor de Relações Públicas das Organizações nessas ações realizadas? Para buscar uma resposta restringiu-se o campo de atuação à Cidade de Campinas e região metropolitana, no Estado de São Paulo, para estudo de casos.

A Realidade da Responsabilidade Social e a atuação de Relações Públicas, num recorte feito em organizações localizadas na cidade de Campinas ${ }^{5}$ e região metropolitana, Estado de São Paulo.

As organizações pesquisadas do $2^{\circ}$ Setor:

Empresa $n^{\circ}$ 1: A unidade pesquisada possui 900 funcionários efetivos e 1.500 prestadores de serviços.Tem Setor de Comunicação e Relações Públicas com dois escritórios de Comunicação Corporativa: um na Europa e outro no Brasil/Centro Empresarial - São Paulo.

A Área de Comunicação Social e Eventos possui dois profissionais de relações públicas e a pessoa responsável pelo setor é relações públicas e pós-graduada em Marketing.

Em suas ações de responsabilidade social, a empresa atende de forma estruturada muitas solici- tações de patrocínios, doações e visitas. Além disso, tem um grupo interno constituído por seus empregados e por meio dele também consegue viabilizar muitas solicitações sociais.

A empresa sempre atendeu solicitações vindas da comunidade, mas esses registros ficaram com a área de Comunicação Social e podese informar, oficialmente, que é desde 1990. E pela outra frente que tem para atendimento de solicitações sociais, o trabalho voluntário do grupo interno, a partir de 1999.

Essas ações são dirigidas internamente, há um grupo de trabalho para levantamento das entidades que serão assistidas no ano, e existem entidades fixas, além das eventuais geradas por demandas que chegam para a área de Comunicação.

O planejamento e a implantação dessas ações de responsabilidade social são sempre da alçada da área de comunicação social. Ocorrem durante todo $o$ ano porque entram como ações do planejamento estratégico anual da empresa.

As estratégias utilizadas para implantar essas ações partem desse planejamento anual e contemplam campanhas de arrecadação de sangue, de brinquedo, de alimentos etc. Externamente, divulga-se e dimensiona-se por meio dos programas de relacionamento com a comunidade - Portas Abertas (evento) e Ambiente Empresa (informativo trimestral). Internamente, compartilha-se com o grupo interno (Grupo Amigos Voluntários) todas as demandas sociais que surgem no dia-a-dia e leva-se para discussão/decisão nas reuniões mensais.

A empresa decidiu realizar ações de responsabilidade social porque o termo responsabilidade social ganha dimensão nos dias de hoje, mas ela 
é considerada uma empresa cidadã de longa data, pela forma como sempre está presente e atende a comunidade.

O retorno dessas Ações para a empresa é observado na preservação da imagem institucional, à medida que essas ações se somam às outras de grande importância, por exemplo, ações de desenvolvimento sustentável.

A divulgação dessas ações é feita por meio de boletins para a comunidade. Essas publicações são editadas e distribuídas pela área de Comunicação Social para órgãos públicos, entidades assistenciais, sociedades amigos de bairros e universidades. O objetivo dessas publicações, além de informar os públicos sobre as entidades assistidas, é mostrar o envolvimento da empresa nos importantes projetos para a comunidade.

Empresa $n^{\circ} 2$ : Atua no ramo de embalagens. Iniciou suas atividades no Brasil em 1957. Possui mais de 1000 funcionários na filial pesquisada.

A empresa tem setor de comunicação/relações públicas e a pessoa responsável por ele tem formação em relações públicas, ocupando o cargo de direção.

Realiza, como ações de responsabilidade social, muitos programas de educação ambiental, voluntariado, ações sociais nos municípios onde atua, apoio à saúde, educação e outras. A empresa deu início a essas ações há mais de 20 anos e são dirigidas a escolas, comunidades onde atua, universidades etc.

Os setores da empresa responsáveis pelo planejamento e pela implantação dessas ações de responsabilidade social são as áreas de Comunicação, Recursos Humanos, Meio Ambiente.

Essas ações têm freqüência constante, mais de uma vez por mês. As estratégias utilizadas para implantar essas ações são folders e todo tipo de comunicação impressa, vídeos, palestras de conscientização, doações diversas etc.

A empresa decidiu realizar ações de responsabilidade social porque se preocupa com o desenvolvimento social/econômico do país e, principalmente, das comunidades onde está inserida.

Além disso, as ações ambientais visam a preservação do ecossistema. A responsabilidade social faz parte da visão e da missão da empresa.

O retorno dessas ações para a empresa tem sido funcionários mais conscientes sobre a necessidade de preservar o meio ambiente e comprometidos com o processo, uma comunidade mais forte e o fortalecimento de sua marca.

Organizações pesquisadas do $3^{\circ}$ Setor:

Entidade $n^{\circ}$ 1: É uma ClínicaEscola Especial e Centro de Referência Nacional no tratamento de Portadores deNecessidadesEspeciais na área da saúde mental. Possui atualmente 22 funcionários, entre eles um estagiário de Psicologia e uma estagiária de Relações Públicas.

A instituição desenvolve atividades de comunicação/relações públicas, tais como: programa de visitas, eventos internos e externos, relações com a imprensa, busca de patrocínios, apoios, permutas, gestão da responsabilidade social.

Utiliza para desenvolver essas atividades: quadro de avisos, jornal, folder, flyer/panfleto, programa de visitas, press-release, correspondências (ofício, carta, memorando, circular, requerimento).

O setor responsável por essas ações é o Departamento de Comunicação, coordenado por uma pessoa

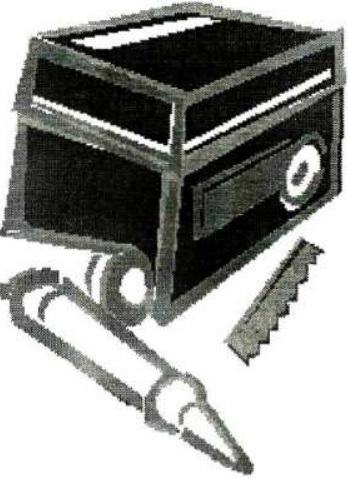

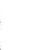


com formação em Relações Públicas.

Atualmente, a instituição não tem dificuldades financeiras, porém, existe um planejamento e ações estratégicas do Departamento de Comunicação para divulgação e captação de novos educandos especiais.

Empresas privadas e públicas desenvolvem Ações de Responsabilidade Social na instituição. A entidade também desenvolve um trabalho de responsabilidade social, subsidiando o tratamento de cerca de $20 \%$ dos educandos, por meio do Programa de Bolsas.

Entidade $n^{\circ} 2$ : Há 15 anos tem por finalidade o atendimento de 300 portadores do virus HIV/Aids que vivem em situação de exclusão social, com objetivo de melhorar a qualidade de vida dos portadores e reintegrálos à família e à sociedade. Possui 30 funcionários e 122 voluntários.

Os voluntários atuam nas diversas áreas: departamentos, sócios contribuintes, voluntários, recursos humanos, comunicação, eventos, contabilidade, serviço social, cozinha, limpeza, saúde etc. e mantêm freqüência regular.

São executadas várias atividades de comunicação/relações públicas, tais como: programa de visitas, eventos internos, eventos externos, relações com a imprensa, busca de patrocínios, apoios, permutas, campanhas com público externo.

Utilizam como instrumentos para desenvolver essas atividades: jornal mural, quadro de avisos, boletim, folder, flyer/panfleto, correspondências (oficio, carta, memorando, circular, requerimento).

Esse trabalho é de responsabilidade do setor de Relações Públicas, que tem uma pessoa com formação superior nessa área, auxiliada por um estudante de Relações Públicas.

No momento da pesquisa, a instituição passava por dificuldades financeiras, e para reverter a situação, o setor de Relações Públicas planejava implantar uma campanha para economia de gastos, captação para aumentar o quadro de associados e potencializar os meios de captação existentes.

Organizações privadas e públicas desenvolvem ações de responsabilidade social na instituição.

A pessoa entrevistada acrescentou que a instituição tem uma profissional de Relações Públicas, ligada mais a planejamento e à execução de eventos, por isso, não consegue desenvolver todas as ações necessárias de comunicação. Segundo ela, seria necessário mais um profissional de comunicação para assessorar a profissional existente.

Análise dos dados obtidos com relação às organizações do $2^{\circ}$ Setor

Ambas as organizações pesquisadas têm setor de Relações Públicas, com profissionais com formação superior nessa área. Ambas realizam voluntariado e ações de responsabilidade social em áreas como meio ambiente, saúde, educação etc. Iniciaram essas ações há muitos anos, com caráter filantrópico que se transformou em ações efetivas.

$\mathrm{Na}$ primeira, essas ações são dirigidas a associações e centros sociais, e há atendimentos a pedidos eventuais, que chegam durante todo o ano. Na segunda, as ações são destinadas a escolas, comunidade, universidades, dentre outros.

Em ambas, o setor de Relações Públicas está envolvido nessa atividade, mas com a participação de outros setores, como recursos humanos e meio ambiente, num trabalho integrado. As ações realizadas têm freqüência irregular. Algumas são pontuais, outras esporádicas.

Utilizam, como estratégia dessas ações, comunicações dirigidas escritas, impressas e eletrônicas.

A decisão de serem empresas 
socialmente responsáveis foi visando o aspecto humanitário e o fortalecimento da marca.

O retorno tem sido a preservação da imagem institucional, funcionários mais conscientes sobre a necessidade de preservar o meio ambiente e comprometidos com o processo, uma comunidade mais forte e o fortalecimento da marca.

Análise dos dados obtidos com relação às organizações do $3^{\circ}$ Setor

Essas organizações são receptoras de grande parte das ações de responsabilidade social do $2^{\circ}$ Setor.

Ambas as organizações pesquisadas têm setor de Relações Públicas dirigidos por profissionais com formação superior na área.

A primeira possui um organizado planejamento para os programas de relações públicas; a segunda concentra as atividades de relações públicas quase que apenas na organização de eventos. Ambas recebem ações de responsabilidade social de organizações privadas e públicas. A segunda conta também com o trabalho de voluntários.

O objetivo do estudo dessas duas organizações foi constatar a presença do setor de Relações Públicas também nessas organizações de pequeno porte. Foi, ainda, interesse mostrar a importância do setor de Relações Públicas como elo entre a organização e seus diversos públicos, principalmente na captação de recursos, mola mestra da sobrevivência do terceiro setor. Constata-se que muito há para ser feito no terceiro setor, cuja proposta é suprir a deficiência do Estado, e relações públicas têm, seguramente, em suas atividades as estratégias para isso. Não será, porém, feito aqui um estudo sobre as relações públicas no $3^{\circ}$ Setor, pois esse tema é objeto de um próximo projeto a ser desenvolvido pela pesquisadora, na
Faculdade de Relações Públicas da PUC-Campinas.

Resultados da Pesquisa

A atuação das organizações do $2^{\circ}$ Setor quanto às ações de responsabilidade social é uma realidade, com tendência a grande crescimento. Quanto mais cresce o volume de ações de responsabilidade social do $2^{\circ}$ Setor, mais cresce o número de organizações do $3^{\circ}$ Setor.

Quanto à atuação de relações públicas nas ações de responsabilidade social das organizações do $2^{\circ}$ Setor, foi possível observar, pelos contatos mantidos e dados colhidos, que há uma participação do setor de Relações Públicas, mas não é esse setor que faz a coordenação geral das ações de responsabilidade social dessas empresas privadas pesquisadas.

Observou-se que o setor de Relações Públicas tem todas as suas outras atividades pontuadas, planejadas e efetivadas dentro de um cronograma pré-estabelecido; no entanto, as ações de responsabilidade social não recebem um tratamento que pode ser considerado como uma atividade de caráter inadiável, embora só o fato de elas existirem nessas organizações já seja muito positivo.

A divulgação das ações de responsabilidade social realizadas por essas organizações pesquisadas é feita por meio de boletins e relatório público anual.

A atuação de relações públicas nas organizações do $3^{\circ}$ Setor foi notada claramente, embora sem toda a força que essa atividade possui.

Diante desses resultados, a pesquisadora, que também é orientadora de TCC - Trabalhos de Conclusão de Curso (Projetos Experimentais $^{6}$ ) na Faculdade de Relações Públicas da PUC-Campinas, instruiu suas equipes de alunos no sentido de proporem também, para 
${ }^{6}$ Projetos Experimentais são trabalhos de conclusão de curso realizados para clientes reais (organizações que não possuam setor/departamento/ gerência de Relações Públicas), orientados por professores. Depois de concluido, o projeto é apresentado para avaliação a uma banca examinadora da qual o cliente é membro. seus clientes, programas de Relações Públicas focados na responsabilidade social. Para citar alguns exemplos, mencionam-se os mais recentes projetos experimentais, realizados em 2004 pelos alunos concluintes:

1 - Cliente:

Ramo: estética e beleza Funcionários: 75

Programa de Responsabilidade Social proposto: Salão Solidário

Estratégias para implantação do programa menciondo:

a) Aplicando conhecimento: aulas e cursos gratuitos em instituição de apoio a mulheres carentes, visando contribuir para que elas gerem seu próprio sustento;

b) Tesoura do Bem: serviços gratuitos de corte e costura, manicure e podologia, para um lar de senhoras idosas em Campinas, pois idoso não precisa só de cobertores e remédios;

c) Salão da Solidariedade: arrecadação interna, em datas especiais, para doações;

d) Pintando a Ecologia: adoção de uma tartaruga do Projeto Tamar. A preservação da espécie é também uma forma de cultivar a beleza ecológica.

2-Cliente:

Ramo: Laboratório de análise e prestador de assitência médicohematológica.

Funcionários: 374 , em três unidades.

Programa de Responsabilidade Social proposto: Fazendo a Diferença

Estratégias para implantação do programa mencionado:

a) Barra Solidária: Campanha de conscientização para doação de sangue, veiculada na barra de hollerith e barra de contas de água e energia elétrica, visando ampliar a divulgação e conscientizar os funcionários e a comunidade;

b) Participando da Vida: stand para divulgação de campanha de conscientização para doação de sangue, instalado em empresas de grande porte, visado também diminuir o preconceito e as dúvidas com relação à doação;

c) Uma Lição de Vida: palestras sobre a importância da doação de sangue e sobre doenças sexualmente transmissíveis, para escolas de $1^{\circ}$, $2^{\circ}$ e $3^{\circ}$ graus, visando a conscientização e a prevenção;

d) Dia do Doador Feliz: realização de evento em fast-food para promover um laboratório, divulgar a importância da doação de sangue e arrecadar verbas;

3-Cliente:

Ramo: Mercado de Cestas

Básicas. Funcionários: 250

Programa de Responsabilidade Social proposto: Fazendo a Nossa Parte

Estratégias para implantação do programa mencionado:

a) Concurso com Escolas da Periferia: elaboração de redação, com premiação de três meses de doação de alimentos para complemento da merenda escolar;

b) Doação de Cestas para Instituições do $3^{\circ}$ setor, em datas comemorativas:

c) Adoção de um Animal do Bosque: visando colaborar com a preservação de uma área de lazer centenária, que passa por dificuldades, fará essa ação socioambiental.

\section{4-Cliente:}

Ramo: Desenvolvimento de Projetos, prestação de serviço e vendas de forjamento de peças a quente e a frio. Funcionários: 16

Programa de Responsabilidade Social proposto: FAV Cidadão

Estratégias para implantação do programa mencionado:

a) Apoio a Escolas da Periferia: disponibilizando seus serviços especializados para conserto e 
manutenção do mobiliário;

b) Iniciação de Aprendizado em Parceria com o SENAC: oferecimento de estágio remunerado para alunos do Senac, visando colaborar para a complementação da sua formação.

\section{5-Cliente:}

Ramo: Fornecedor de Matériaprima Farmacêutica. Funcionários: 25

Programa de Responsabilidade Social proposto: Nostra Responsabilidade

Estratégias para implantação do programa mencionado:

a) Contratação de funcionário com Necessidades Especiais: Independente da exigência da Lei;

b) Campanha de Apoio à saúde da $3^{\mathrm{a}}$ idade: parceria com farmácias, propondo descontos especiais em remédios com formulações que usem produtos da empresa;

c) participação na Campanha "Dia do Doador Feliz", realizada por laboratório de Análises de Campinas: contribuir para a viabilização de campanha tão significativa para a coletividade.

Dessa forma, será possível capacitar profissionais para atuarem com as diversas organizações e, ao mesmo tempo, abrir espaço para o profissional de Relações Públicas e solidificar a atividade como fundamental para as organizações desenvolverem esse trabalho que beneficia a todos que fazem parte do contexto. Também a produção dos alunos será um acervo de grande valia para intercâmbios com outras IES, organizações públicas, privadas e do terceiro setor da região.

A pesquisadora também publicou, no jornal Correio Popular, ${ }^{7}$ um artigo intitulado Bosque dos Jequitibás- um espaço para ações de responsabilidade socioambientais, dirigido a organizações do segundo setor da região metropolitana da cidade de Campinas, visando incentivá-las a recuperar um bosque centenário da cidade, com a adoção de seus animais. Pretende-se que a proposta seja, primeiro, acolhida pela Câmara Municipal da cidade e, depois, adotada pelo empresariado. O jornal Correio Popular está incentivando para que a proposta seja viabilizada; por conta disso, publicou também longa reportagem, denominada Projeto incentiva adoção de animais que vivem no Bosque, com chamada de capa Projeto propõe bicho adotado no Bosque, em edição de domingo.

\section{Conclusão}

A responsabilidade social é uma realidade nas organizações do $2^{\circ}$ Setor que foram pesquisadas. Percebe-se, porém, que ainda há muito para se fazer no sentido de efetivamente incorporá-las a algum setor das organizações e para estabelecer o setor que será o coordenador-geral dessa atividade.

É também possível observar que ainda existe, dada a indeterminação do setor para esse fim, a tendência de essa atividade ficar como acúmulo de serviço para alguns setores da organização. Mas as organizações já estão compreendendo que investir em ações de responsabilidade social não é custo, mas investimento, pois elas pensam em fortalecimento da marca, além do caráter humanitário.

Confirmou-se também que as ações de responsabilidade social fortalecem a marca; que as organizações socialmente respon-sáveis são mais valorizadas pelos consumidores e que Relações Públicas pode ser o setor, nas organizações do $2^{\circ}$ setor, a coordenar as ações de responsabilidade social.

Foram avaliadas as ações de responsabilidade social das organi-
${ }^{7}$ Correio Popular é o principal jornal da cidade de Campinas/SP, com circulação diária. 
zações, identificadas a atuação de relações públicas e apresentadas formas de como relações públicas pode implementar ações de responsabilidade social nas mais diversas organizações, como foi demonstrado nos diversos clientes de projetos experimentais da Faculdade de Relações Públicas da PUC-Campinas.

Acredita-se que a fórmula para uma sociedade mais igualitária poderá ser:

$2^{\circ} \mathrm{S}(\mathrm{rs})+\mathrm{RP}$ (estratégias) $+3^{\circ} \mathrm{S}$ (distribuição) $=$ redução da desigualdade social do País.

Finalmente, confirmado que o $2^{\circ}$ Setor está investindo em ações de responsabilidade social, que a atividade de relações públicas também participa na implementação dessas ações e que o $3^{\circ}$ Setor também abre espaço para a atuação de relações públicas, é positivo recomendar que as Faculdades de Relações Públicas incluam em seus TCCs (Trabalhos de Conclusão de Curso) Programas de Relações Públicas voltados também para a responsabilidade social. № $2^{\circ}$ Setor, desenvolvendo programas com ações voltadas para os públicos de interesse. No $3^{\circ}$ Setor, agindo no todo da organização, aplicando as técnicas necessárias para eficácia da região.

\section{Abstract}

This article focus on detecting which is the public relations role on the organizations social responsibilities. Studies have been made of cases into two companies of the $2^{\text {nd }}$ Sector, which have a public relations field, with a professional actually working; and two of the $3^{\text {rd }}$ Sector, which also have the same field and professional. Taking Campinas/SP and its area as a sample, the new national researches made by IPEA were confirmed, regarding to the strong and growing participation of the $2^{\text {nd }}$ Sector at the social area. The organizations of the $3^{\text {rd }}$ Sector also confirm this $2^{\text {nd }}$ Sector's interest.
With regarding to the acting of the public relations, it is possible to realize that the sector has participation on the administration of the social responsibilities, as well as on the organizations of the $3^{\text {rd }}$ Sector, butit's necessary to go forward. The description of the job developed by the public relations, itself, indicates that he is able to be, also, the head of the $2^{\text {nd }}$ Sector's social responsibility action and, to the $3^{\text {rd }}$ Sector, bring effectiveness to the mandate. Keywords: Public Relations; Social Responsibility; Research.

Referência

ASHLEY, Patrícia Almeida.(org). Ética e Responsabilidade Social nos Negócios. São Paulo: Ed. Saraiva, 2002. BARROSO, Luiz Felizardo. PPPs e as pequenas e médias empresas. Caderno Legal e jurisprudência. Jornal Gazeta Mercantil. p.1- 14/01/05- ano III $n^{\circ} 1028$.

BIVINS, Thomas. Handbook for Public Relations Writing. Illinois-USA: NTC, 1995.

CESCA, Cleuza G. Gimenes. Comunicação Dirigida Escrita na Empresa -Teoria e prática. $3^{a}$ edição. São Paulo: Summus Editorial, 1995.

.Cesca, Wilson. Estratégias

Empresariais Diante do Novo Consumidor. São Paulo:Summus Editorial, 2000.

CAPRIOTTI, Paul. Planificación Estratégica de la Imagen Corporativa. Barcelona: Ariel Comunicación, 1999. CORRADO, Frank M. A Força da Comunicação. São Paulo: Makron Books, 1994.

DONAIRE, Denis. Gestão Ambiental na Empresa. São Paulo: Atlas, 1996. DOTY, Doroty I. Publicity and Public Relations. New York: Barron's, 1990. ESTEVES, Sérgio A. P. (org). O Dragão e a Borboleta sustentabilidade e responsabilidade social nos negócios. São Paulo: Axi Mundi-AMCE, 2000.

FINTAN, Lawless. A Responsabilidade Social das Empresas Multinacionais no $3^{\circ}$ setor. Tese. Depto filosofia da PUCRio de Janeiro, 1993.

FORTES, Waldyr Gutierrez. Relações Públicas: processo, funções, tecno- 
logias e estratégias: Ed. UEL, 1998. Guia Exame. Boa Cidadania Corporativa. São Paulo: Editora Abril, dez/2003. Guia Exame. Boa Cidadania Corporativa. São Paulo:.Editora Abril, dez/2004. HARRIS, Thomas L. The Marketer's guide to Public Relations. New York: John Wiley \& Sons, 1991.

JORNAL Correio Popular. Caderno Cidade. 07/14 setembro 2004.

KUNSCH, Margarida M.K. Planejamento de Relações Públicas na Comunicação Integrada. 4 ed. revisada e ampliada. São Paulo: Summus Editorial, 2000.

KOTLER, Philip. Marketing para o Século XXI. $5^{\text {a }}$ ed. Tradução Cristina Bazán. São Paulo: Ed.Futura, 2000.

LLOYD, Herbert e Peter. Relações Públicas: as técnicas de comunicação no desenvolvimento das empresas. Lisboa: Presença, 1985. . Relaciones Publicas. Madri:

Ed.Pirámide, 1990.

MARTINELLI, Antônio C. $3^{\circ}$ Setor: Desenvolvimento Social Sustentado. Editora Paz e Terra. Rio de Janeiro, 1997.

MELO NETO, Francisco P. e DROES, César. Gestão da responsabilidade social corporativa. São Paulo: Qualitymark, 2001.

. Responsabilidade social \&

Cidadania empresarial. São Paulo: Qualitymark, 2002.

MOTTA, Paulo Roberto. Transformação Organizacional. São Paulo: Qualitymark, OLIVER, Richard W. Como Serão as Coisas no Futuro. São Paulo: Negócio Editora, 1999.

PELIANO, Anna Maria T. M. (Coord). Iniciativa privada e o espírito públicoum retrato da ação social das empresas do sudeste brasileiro. IPEA, Brasília, 2000.

SCHERER-WARREN, I. Cidadania sem Fronteiras: ações coletivas na era da globalização. São Paulo: Hucitec, 1999.

SOROR, George. Globalização. Editora Campus, São Paulo: 2002.

TACHIZAWA, Takeshy. Gestão Ambiental e Responsabilidade Social Corporativa. São Paulo: Ed. Atlas, 2002. TOFFLER, A \& H. Criando uma Nova
Civilização: a política da terceira onda.

5 ed. Rio de Janeiro: Record, 1997.

WILSON, Grahan. Fazendo Acontecer a Mudança. São Paulo: Editọra Saraiva, 1996.

www.ethos.com.br

www.fundabrinc.org.br

www.gife.org.br

www.ipea.com.br

www.rits.org.br

www.terceirosetor.org.br

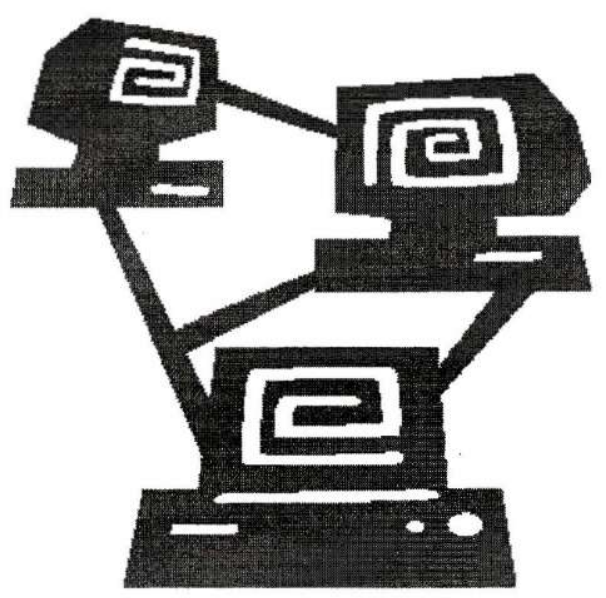

Data do recebimento: 10/09/2006

Data do aceite: 06/10/2006 